\title{
Synthesis and Characterization of PVA Assisted Sr- Hydroxyapatite Using Hydrothermal Coupled Microemulsion Method
}

\section{VENDA IRUDHAYAM}

SACRED HEART COLLEGE (AUTONOMOUS)

THAMIZHARASI VEERABATHIRAN

SACRED HEART COLLEGE (AUTONOMOUS)

COLLINS ARUN PRAKASH VICTOR ( $\square$ collinsnanobio@gmail.com )

SACRED HEART COLLEGE (AUTONOMOUS)

\section{Research Article}

Keywords: Hydroxyapatite, Biomaterials, Strontium, PVA, hydrothermal method, Microemulsion method

Posted Date: June 2nd, 2021

DOI: https://doi.org/10.21203/rs.3.rs-576758/v1

License: (c) This work is licensed under a Creative Commons Attribution 4.0 International License.

Read Full License 


\section{Abstract}

Hydroxyapatite is a bioceramic material and it is one of the most important inorganic compounds which are extensively used in several forms as a bone substitute material. Hydroxyapatite is chemically represented as $\left(\mathrm{Ca}_{10}\left(\mathrm{PO}_{4}\right)_{6}(\mathrm{OH})_{2}\right)$, and is chemically and crystallographically similar to the human hard tissue. The hydroxyapatite nanoparticle is mainly used in orthopaedic and dental applications due to its properties of bioactivity, osteoconduction, biocompatibility and non-toxicity. In this research work, poly vinyl alcohol assisted strontium substituted hydroxyapatite nano powders was synthesised by conventional hydrothermal coupled microemulsion method using dimethyl sulfoxide and hexane. It is well known that strontium stimulates bone formation, reduction bone resorption and it is also used to osteoporosis diseases, while poly vinyl alcohol (PVA) helps in controlling the morphology and it is beneficial for artificial bone formation and possess excellent bioactivities properties. The structure, chemical composition and morphology were investigated by different techniques such as XRD, FTIR, SEM and MTT assay. The results indicated that the poly vinyl alcohol assisted Sr substituted hydroxyapatite nanoparticle has a uniform spherical morphology, smaller particle size and with no impurities. The biomedical application studies of the as-synthesised material are yet to be studied.

\section{Research Highlight}

The significant research findings reported in this paper are as follows

$\sqrt{ }$ Polyvinyl alcohol assisted Sr substituted hydroxyapatite nanoparticles have been successfully synthesized through conventional hydrothermal coupled microemulsion method using DMSO/cyclohexane/water combination as a novel technique.

$\sqrt{ }$ PVA play an important role in controlling the morphology and also the reduction of particle size that can result in fine nanometer sized hydroxyapatite powders.

$\sqrt{ }$ The PVA assisted strontium-hydroxyapatite powder has showed excellent biocompatibility and bioactivity due to the addition of strontium.

$\sqrt{ }$ Strontium plays an important role in osteoporosis treatment and enhancement of bone demineralization as it is related with an increase in bone formation and decrease in bone resorption.

$\sqrt{ }$ This novel biocompatible and bioactive hydroxyapatite prepared by using strontium as a template is promising candidates for biomedical applications.

\section{Introduction}

Hydroxyapatite (HAP) is the most important mineral form of calcium phosphate salt existent as inorganic phase in human classified tissues i.e., bone and teeth [1] and it is chemically represented as $\mathrm{Ca}_{10}$ $\left(\mathrm{PO}_{4}\right)_{6}(\mathrm{OH})_{2}$. The capability of the human body to redevelop bone components that are damaged or lost 
is restricted. For this purpose, materials are to be developed that can sufficiently change bone tissue, specially mineralized tissue includes teeth and bone. Therefore researches on the preparation of hydroxyapatite nanoparticles has grown with much importance currently as bone mineral contains hydroxyapatite in the form of spherical/rod like nanoparticles. The synthesized hydroxyapatite powders have excellent properties such as biocompatibility, osteoconductivity, bioactivity and non-inflammatory as well as non-toxicity behaviour [2-6]. Therefore, HAP is an appropriate material for biomedical applications and it has been commonly used for hard tissue regeneration and repair [7]. HAP has also been used for several applications including drug and gene delivery, gas sensor, chromatography, water purification and photo catalytic [8-10] etc. Meanwhile the application of HAP truly depends on the morphology, precursor sources, particle size, crystallinity and phase purity of nanoparticles etc. [11]

Strontium can exist in the mineral phase of bone, mainly at regions of high metabolic turnover and its useful effect in the osteoporosis treatment $[12,13]$. Accordingly, several methods are reported for the nonstoichiometric hydroxyapatite that can be prepared with incorporation of anionic and cationic substitution including $\mathrm{Na}^{+}, \mathrm{Mn}^{2+}, \mathrm{Mg}^{2+}, \mathrm{Sr}^{2+}, \mathrm{Zn}^{2+}, \mathrm{F}^{-}, \mathrm{OH}^{-}$etc., Among these ions, the strontium element has been established to develop vital function in growing and also bone repair [14]. It can regulate the degradation, improve the mechanical strength of the hydroxyapatite [15], and positively control their bioactive properties including osteoconduction. Strontium is well-known to act an significant role in both the stimulation of bone growth in osteoporotic treatment and reduction of bone resorption during bone remodelling [16], which naturally exists in bone and teeth $[17,18]$. The strontium and calcium share the properties of group 2A elements, without much difficulty. Furthermore, strontium substituted hydroxyapatite has attracted enormous attention because it is a bone seeking element that appears a beneficial influence on bone growth and its excellent physical, chemical and structural parallel to Calcium in hydroxyapatite [19].

There are many techniques present in the literature for the preparation of hydroxyapatite and substitute hydroxyapatite nanoparticles such as ultrasound system [20, 21], precipitation method [22], sol-gel method [23], hydrothermal system [24, 25], microemulsion technique [26], hydrothermal coupled microemulsion method etc. [27, 28]. Nevertheless, most of the methods suffer from achieving the spherical morphology, uniform size distribution, more agglomeration, uncontrolled long term aging and aggregation due to stringent processes. Amongst these methods, the hydrothermal coupled microemulsion method is suitable for the preparation of HAP nanoparticles. Hydrothermal methods provides well crystallinity, phase purity and improved control over stoichiometry but more agglomeration and a very big size distribution [29], while microemulsion method offers controls the particle size, uniform morphology and to avoid agglomeration, ease of preparation with produced nano-particles. Consequently, combining these two methods may offer better preparation method for hydroxyapatite nanoparticles.

The present work mostly focuses on the formation of hydroxyapatite with crystallized and controlled morphology of hydroxyapatite nanoparticles using PVA by hydrothermal coupled microemulsion method. Polyvinyl alcohol is a polymer, non-ionic surfactant with good biocompatibility, excellent bioactivities, non-toxicity, more elastic modulus and water content [30-32,] as well as biodegradable polymer [33]. The 
polyvinyl alcohol hydrogel possesses high potential for their use in tissue engineering and it can also play as a feasible alternative of current artificial bone. Polyvinyl Alcohol (PVA) is widely used in biochemical, pharmaceutical and biomedical applications [34-37] including orthopaedic devices, wound dressings, drug delivery devices [38] and artificial organs [39]. The polyvinyl alcohol is most effective templates because it controls the morphology and reduces the particle size with preventing agglomeration.

In the current work, we report that the preparation of polyvinyl alcohol assisted Sr substituted hydroxyapatite nanoparticles by hydrothermal coupled microemulsion method using DMSO/cyclohexane/water combination. The results have shown that, the preparation of strontium substituted HAP powder has well phase purity with crystallinity and do not show more agglomeration with impurity, uniform spherical morphology and smaller particle size was reached through hydrothermal coupled microemulsion method. The as-achieved hydroxyapatite powders were characterized by different analytical techniques.

\section{Materials And Methods}

\subsection{Chemicals and Reagents}

In the conventional hydrothermal coupled microemulsion synthesis, analytical grade $\mathrm{Ca}\left(\mathrm{NO}_{3}\right)_{2} \cdot 4 \mathrm{H}_{2} \mathrm{O}$, and $\left(\mathrm{Na}_{2} \mathrm{HPO}_{4}\right)$, were used for preparing calcium and phosphate precursor materials for hydroxyapatite synthesis and polyvinyl alcohol, strontium nitrate, hexane, DMSO and ammonia $\left(\mathrm{NH}_{3}\right)$ were purchased from Merck, India was used as such. The entire chemicals were of analytical grade and deionized water (DI) was used during the experimental process.

\subsection{Preparation of Hydroxyapatite powder}

Hydroxyapatite nano-particles and polyvinyl alcohol assisted strontium substituted hydroxyapatite powders were synthesised by hydrothermal coupled microemulsion method according to the following process: $0.5 \mathrm{M} \mathrm{Ca}\left(\mathrm{NO}_{3}\right)_{2} \cdot 4 \mathrm{H}_{2} \mathrm{O}$ and strontium nitrate were dissolved in (DI) water with continuous stirring for 30 minutes to make it homogeneous and $0.3 \mathrm{M} \mathrm{Na}_{2} \mathrm{HPO}_{4}$ solution was dissolved in deionized water. The $\mathrm{Ca}\left(\mathrm{NO}_{3}\right)_{2} \cdot 4 \mathrm{H}_{2} \mathrm{O}$ with strontium nitrate solutions were subsequently added drop by drop into $\mathrm{Na}_{2} \mathrm{HPO}_{4}$ solution. This solution was used for the aqueous phase and to maintain the $\mathrm{Ca}^{2+} / \mathrm{PO}_{4}{ }^{3-}$ ratio as 1.67. PVA was added as a surfactant while dimethyl sulfoxide was used as a co-surfactant and hexane as an oil phase. These solutions were dissolved in (DI) water with continuous stirring for $1 \mathrm{~h}$ to produce an oil phase. The obtained oil phase was then added dropwise into the calcium phosphate mixture. The obtained white suspensions were strongly stirred for $2 \mathrm{~h}$ until a clear solution was obtained. The $\mathrm{pH}$ of the solution was adjusted to 10 by adding $\mathrm{NH}_{3}$ solution. Then the resulting solutions were transferred to autoclaves followed by heated at $120^{\circ} \mathrm{C}$ for $3 \mathrm{hrs}$. Afterwards the white precipitate was filtered and washed many times with (DI) water and ethanol followed by drying at $100^{\circ} \mathrm{C}$ for $3 \mathrm{hrs}$. The obtained powder was then calcined and sintered finally to achieve nano-hydroxyapatite powder. The 
preparation of hydroxyapatite was repeated without the addition of surfactant and with PVA. The obtained product was characterized with different analytical techniques.

\section{Results And Discussion 3.1. FTIR analysis}

The hydroxyapatite powder and polyvinyl alcohol assisted strontium substituted hydroxyapatite powder synthesised by conventional hydrothermal coupled microemulsion method was investigated by FTIR technique. The characteristic peaks of phosphate group, hydroxyl group and absorbed water are clearly detected in Fig. 1. The $v_{1}$ group frequency is detected at $966 \mathrm{~cm}^{-1}$ which is due to symmetric stretching vibrational mode of phosphate group and the $v_{2}$ vibration of phosphate group was found at $475 \mathrm{~cm}^{-1}$ which could be attributed to symmetric bending mode of phosphate group. The high intensity peaks occurs at 1040 and $1096 \mathrm{~cm}^{-1}$ is due to asymmetric stretching vibration mode of phosphate group $v_{3}$. The peaks found at $559 \& 606 \mathrm{~cm}^{-1}$ corresponds to asymmetric bending mode of the phosphate group $v_{4}$. The sharp peak at $3580 \mathrm{~cm}^{-1}$ corresponds to symmetric stretching vibration of the hydroxyl group while the medium peak observed at $624 \mathrm{~cm}^{-1}$ is due to $\mathrm{OH}$ group. The broad peak detected at $3433 \mathrm{~cm}^{-1}$ is assigned to the adsorbed lattice water. The peak observed at $1635 \mathrm{~cm}^{-1}$ corresponds to $\mathrm{OH}$ bending mode. The obtained values for Fig. 1 ( $a$ and $b$ ) are shown in Table. 1. In Fig. 1 (a-c) all characteristic peaks for hydroxyapatite are present in FTIR spectrum and no impurities were noted [40]. Hence the FTIR result suggests that the quality of our sample is good.

Table 1

FTIR spectral assignment of the functional groups

Functional group and Vibrational frequency

\begin{tabular}{|llllllll|}
\hline Sample & OH & \multicolumn{5}{c|}{ Phosphate } \\
\hline & Stretching & Lattice water & Bending & $v_{1}$ & $v_{2}$ & $v_{3}$ & $v_{4}$ \\
\hline HAP & $3560 \& 639$ & 3441 & 1643 & 985 & 489 & $1022 \& 1078$ & $588 \& 601$ \\
\hline HAP-PVA & $3524 \& 633$ & 3496 & 1625 & 956 & 486 & $1023 \& 1070$ & $550 \& 605$ \\
\hline Sr-HAP-DMSO & $3580 \& 624$ & 3433 & 1635 & 966 & 475 & $1040 \& 1096$ & $559 \& 606$ \\
\hline
\end{tabular}

\subsection{XRD analysis}

The phase purity and crystallinity of as obtained hydroxyapatite powder was assessed by X-ray diffraction studies. The XRD pattern of the prepared hydroxyapatite powder and polyvinyl alcohol assisted strontium substituted hydroxyapatite powder is shown in Fig. 2 (a-c). The sharp and major characteristic peaks are detected at $2 \theta$ values in the range of $25.90,31.79,32.21,32.91,34.08,39.52$, 
$46.67,49.44$ and 53.16 assigned to $002,211,112,300,202,310,222,213$ and 004 planes respectively in pure hydroxyapatite. Correspondingly, lightly broader diffraction peaks appeared at $2 \theta$ values in the range of $25.85,31.76,32.18,32.86,34.05,39.44,46.50,49.34$ and 53.10 correspond to $002,211,112,300,202$, $310,222,213$ and 004 planes respectively in strontium substituted HAP. It can be seen that, the preparation of PVA assisted strontium substituted hydroxyapatite powder are well matched with the standard diffraction data for hydroxyapatite (JCPDS file No 09-0432) and it belong to hexagonal structure [41], no extra peaks of any other phases like TCP can be observed in Fig. 2 (a-c) and hence it could be known that pure nano-sized hydroxyapatite particle could be obtained. It can be clearly observed that, the addition of PVA act a major role in the development of HAP nano-particles and decreases the particle size. The PVA assisted strontium substituted HAP powder indicates well crystallized, smaller particle size with phase purity when compared to HAP powder obtained without surfactant. The grain size of the PVA assisted Sr-substituted HAP powder is found to be lesser when comparing to HAP. Crystallite size are shown below in Table 2 and particle size (D) was calculated by scherrer formula [42],

\section{$D=K \times \lambda / \beta \times \cos \theta$}

\begin{tabular}{|c|c|}
\hline \multicolumn{2}{|c|}{$\begin{array}{l}\text { Table. } 2 \\
\text { Average particle size hydroxyapatite powders by scherrer formula. }\end{array}$} \\
\hline Sample code & Average particle size (nm) \\
\hline HAP & 30 \\
\hline HAP-PVA & 16 \\
\hline HAP-PVA-Sr & 14 \\
\hline
\end{tabular}

The particle size and the surface morphology of the prepared samples were determined by scanning electron microscopic technique. The morphology of the PVA assisted Sr-HAP and hydroxyapatite powders prepared by the conventional hydrothermal coupled microemulsion method are presented in Fig. 3 (a-c). From the SEM images, it can be observed that the synthesised HAP powder without addition of surfactant exhibits a greater numbers of disordered, tightly aggregated particles and the powder is nonuniform in size with an irregular morphology. In Fig. 3 (b and c) shown, the influence of polyvinyl alcohol assisted strontium-HAP powder has resulted in a relatively uniform size distribution, lesser particle size and highly regular morphology when compared to HAP powder obtained without additives. It can be seen that the elongated morphology converted into spherical morphology due to the influence of polyvinyl alcohol and strontium. This was achieved because the surfactants like polyvinyl alcohol have reacted with inorganic substance (calcium and phosphate) in microemulsion system by electrostatic force to form spherical hydroxyapatite. The spherical micelles play as nucleating agent for the development of hydroxyapatite powder and during the reaction, the polyvinyl alcohol-hydroxyapatite compound are 
produced and it could be control the morphology and also the reduction of particle size of obtained hydroxyapatite powder. The spherical nano-hydroxyapatite powder was obtained after the removal of surfactant using calcination and sintering [43]. As a typical result, the preparation of PVA assisted SrHAP powder indicated well control particle size and uniform morphology.

\subsection{In Vitro assay for Proliferation Study: (MTT assay)}

The invitro biocompatibility of PVA assisted strontium-hydroxyapatite sample was evaluated by MTT assay test on osteoblast cell line MG-63 and the effect of PVA assisted strontium-hydroxyapatite powder was analysed based on cell viability of human bone cells. The MG-63 cells lines were cultured with PVA assisted strontium-hydroxyapatite powder for 1 day, 2 days and 3 days and are shown in Fig. 4 (a-l). This MTT assay was carried out in different concentration of PVA assisted strontium-hydroxyapatite particles ranging from $0.7-1000 \mu \mathrm{g} / \mathrm{ml}$. The obtained results indicate that PVA assisted strontium-hydroxyapatite powder MG-63 cell line viability has markedly increased compared to that of control at lower concentration $(0.7 \mu \mathrm{g} / \mathrm{ml})$. The results suggested that the synthesised PVA assisted strontiumhydroxyapatite powder are non-toxic, biocompatibility and bioactivity and therefore quite suitable for cell growth and adhesion in bone tissue engineering. The result also reveal that the PVA assisted strontiumhydroxyapatite powder exhibited about $344 \%$ cell viability for higher concentration after $72 \mathrm{~h}$ of incubation which suggests for fairly well cytocompatibility of the strontium substituted hydroxyapatite.

The MTT assay shown in Fig. 4 (72 h) indicates that the hydroxyapatite powder exhibit no visible cytotoxicity because greater number of osteoblast cell is visible and uniformly distributed. The result indicates that, after $72 \mathrm{~h}$ treatment, the MG-63 cell viability was reached a maximum in all the concentration compared to $24 \mathrm{~h}$ and $48 \mathrm{~h}$ and it is evident from the Fig. 5. The PVA assisted strontiumhydroxyapatite powder showed excellent biocompatibility and bioactivity due to the addition of strontium. As a typical result, the MTT assay showed the cell viability graded in the order: $344 \%<259 \%$ $<241 \%$ for $72 \mathrm{~h}, 48 \mathrm{~h}$ and $24 \mathrm{~h}$. It was found that these polyvinyl alcohol assisted strontium substitution hydroxyapatites were favourable to the proliferation and differentiation of MG-63 cells. This novel biocompatible and bioactive hydroxyapatite prepared by using strontium as a template is promising candidates for biomedical applications.

\section{Conclusions}

Polyvinyl alcohol assisted strontium substituted hydroxyapatite nanoparticle have been successfully synthesized through conventional hydrothermal coupled microemulsion method. The results shown that, the synthesised polyvinyl alcohol assisted strontium substituted hydroxyapatite powder was well crystallized with hexagonal structure and does not show impurity peaks as evident from the FTIR and XRD. The SEM images exhibited that the obtained powders were found to possess improved structural and morphological features such as uniform particle size and size distribution due to the addition of PVA. Hence, it can be concluded that, the hydrothermal coupled microemulsion method with PVA play significant role in regulatory the morphology and also the reduction of particle size that can result in fine nano-sized hydroxyapatite powders. The PVA assisted strontium-hydroxyapatite powder has showed 
excellent biocompatibility and bioactivity due to the addition of strontium. The obtained HAP powder could well serve as favourable candidate in biomedical applications and hence this technique could be a novel approach to synthesis HAP nanoparticles.

\section{References}

1. Pramanik, A.K. Agarwal, and K.N. Rai, Development of High Strength Hydroxyapatite for Hard Tissue Replacement, Trends. Biomater. Artif. Organs, 19, 46 (2005).

2. Agarwala A. Bhagwat, Hydroxyapatite as A Bone Graft Substitute: Use in Cortical and Cancellous Bone, Indian J. of Orthop, 39, 254 (2005).

3. L. Hench, J. Wilson: Surface Active Biomaterials, Science, 226, 630 (1984). https://doi.org/10.1126/science.6093253

4. Yoshinari, Y. Oda, T. Inoue, K. Matsuzaka, M. Shimono, Bone response to calcium phosphate-coated and bisphosphonate-immobilized titanium implants, Biomaterials, 23, 2879 (2002). https://doi.org/10.1016/S0142-9612(01)00415-X

5. Darimont, R. Cloots, E. Heinen, L. Seidel, R. Legrand, In vivo behaviour of hydroxyapatite coatings on titanium implants: a quantitative study in the rabbit, Biomaterials, 23, 2569 (2002). https://doi.org/ 10.1016/s0142-9612(01)00392-1.

6. Descamps, J.C. Hornez, A. Leriche, Manufacture of hydroxyapatite beads for medical applications, J. Eur. Ceram. Soc., 29, 369 (2009). https://doi.org/10.1016/j.jeurceramsoc.2008.06.008

7. Sopyan, M. Mel, S. Ramesh, K.A. Khalid, Porous hydroxyapatite for artificial bone applications, Sci. Technol. Adv. Mater, 8, 116-123 (2007). https://doi.org/10.1016/j.stam.2006.11.017

8. Uskokovic, D.P. Uskokovic, J Nanosized hydroxyapatite and other calcium phosphates: chemistry of formation and application as drug and gene delivery agents, Biomed. Mater. Res, 968, 152-191 (2011). https://doi.org/ 10.1002/jbm.b.31746

9. He, K. Zhang et al., Performance of novel hydroxyapatite nanowires in treatment of fluoride contaminated water, J. Hazard. Mater, 303, 119-130 (2016). https://doi.org/10.1016/j.jhazmat.2015.10.028

10. Piccirrillo, et al., Calcium hydroxyapatite-based photo catalysts for environment remediation: Characteristics, performances and future perspectives, J. Environ Manage, 193, $79-91$ (2017). https://doi.org/10.1016/j.jenvman.2017.01.071

11. Uota, H. Arakawa, N. Kitamura, Synthesis of high surface area hydroxyapatite nanoparticles by mixed surfactant-mediated approach. Langmuri. 21, 4724-4728 (2005). https://doi.org/10.1021/la050029m

12. J. Marie, Strontium ranelate in osteoporosis and beyond: identifying molecular targets in bone cell biology. Mol. Interv, 2010; 10(5):305-12. Epub 2010/11/04. https://doi.org/10.1124/mi.10.5.7 PMID:21045244. 
13. Saidak, P.J. Marie, Strontium signaling: molecular mechanisms and therapeutic implications in osteoporosis. Pharmacol. Ther. 13, 216-26 (2012). https://doi.org/10.1016/j.pharmthera.2012.07.009 PMID: 22820094.

14. C. Cox, P. Jamshidi, L.M. Grover, K.K. Mallick. Preparation and characterisation of nanophase Sr, Mg, and Zn substituted hydroxyapatite by aqueous precipitation. Mater Sci Eng C Mater Biol Appl. 35, 106-14 (2014). https://doi.org/10.1016/j.msec.2013.10.015 PMID: 24411358.

15. Roy, G. Fielding, A. Bandyopadhyay, S. Bose. Effects of Zinc and Strontium Substitution in Tricalcium Phosphate on Osteoclast Differentiation and Resorption. Biomater Sci.; 1 (2013). https://doi.org/10. 1039/C2BM00012A

16. Gentleman, Y.C. Fredholm, G. Jell, N. Lotfibakhshaiesh, et al. The effects of strontium-substituted bioactive glasses on osteoblasts and osteoclasts in vitro. Biomaterials. 31, 3949-56 (2010). https://doi.org/10.1016/j.biomaterials.2010.01.121

17. Boanini, M. Gazzano, A. Bigi, lonic substitutions in calcium phosphates synthesized at low temperature, Acta Biomaterialia, 6, 1882-1894 (2010). https://doi.org/10.1016/j.actbio.2009.12.041.

18. Kawabata, T. Yamamoto, A. Kitada, Physica B: Substitution mechanism of $\mathrm{Zn}$ ions in $\beta$-tricalcium phosphate, Condens. Matter, 406, 890-894 (2011). https://doi.org/10.1016/j.physb.2010.12.022

19. Balamurugan, G. Balossier, P. Torres, J. Michel J.M.F. Ferreira, Sol-gel synthesis and spectrometric structural evaluation of strontium substituted hydroxyapatite. Mater. Sci. Eng. C. 29, 1006-1009 (2009). https://doi.org/10.1016/j.msec.2008.09.005.

20. S. Suslick, S.B. Choe, A.A. Cichowlas, M.W. Grinstaff, Sonochemical synthesis of amorphous iron. Nature 353, 414 (1991).

21. Han, X. Wang, S. Li, Change of phase composition and morphology of sonochemically synthesised hydroxyapatite nanoparticles with glycosaminoglycans during thermal treatment, Adv. Appl. Ceram. 108, 400 (2009). https://doi.org/10.1179/174367609X414134

22. Gentile, C.J. Wilcock, C.A. Miller, R. Moorehead, P.V. Hatton, Process Optimization to Control the Physico-Chemical Characteristics of Biomimetic Nanoscale Hydroxyapatites Prepared Using Wet Chemical Precipitation, Materials 8, 2297 (2015).

23. Wang, M. Li, Y. Lu, Y. Qi, A simple sol-gel technique for preparing hydroxyapatite nanopowders, Mater. Lett. 59, 916-919 (2005). https://doi.org/10.1016/j.matlet.2004.08.041

24. Yan, Y.D. Li, Z.X. Deng, J. Zhuang, X.M. Sun, Surfactant-assisted hydrothermal synthesis of hydroxyapatite nanorods, Int. J. Inorg. Mater. 3, 633 (2001). https://doi.org/10.1016/S14666049(01)00164-7

25. S. Earl, D.J. Wood, S.J, Milne, Hydrothermal synthesis of hydroxyapatite. Journal of Physics: Conference Series, 26, 268-271 (2006). https://doi.org/10.1088/1742- 6596/26/1/064

26. Yuan, S.M. Li, F.K. Mo, D.F. Zhong, Investigation of microemulsion system for transdermal delivery of meloxicam. Int. J. Pharm. 321, 117-123 (2006). https://doi.org/10.1016/j.ijpharm.2006.06.021.

27. Collins Arun Prakash, I. Venda, V. Thamizharasi, E. Sathya, Infuence of DMSO Sr on the Synthesis of Hydroxyapatite by Hydrothermal Coupled Microemulsion Method, J. Inorg. Organometallic. 
Polymers. Matter. 31, 1095-1101 (2021). https://doi.org/10.1007/s10904-020-01723-2

28. M. Taheri et al., Surfactant-assisted hydrothermal synthesis of Fluoridated Hydroxyapatite nanorods, Ceram. Int., 41, 9867-9872 (2015). https://doi.org/10.1016/j.ceramint.2015.04.061

29. Collins Arun Prakash, I. Venda, V. Thamizharasi, E. Sathya, A new attempt on synthesis of spherical nano hydroxyapatite powders prepared by dimethyl sulfoxide - poly vinyl alcohol assisted microemulsion method. Mater. Chem. phys. Sci, 259, 124097 (2021).

https://doi.org/10.1016/j.matchemphys.2020.124097.

30. Yan, Y. Miao, H. Tan, T. Zhou, Z. Ling, Y. Chen, Xing, X. Hu, Injectable alginate/hydroxyapatite gel scaffold combined with gelatin microspheres for drug delivery and bone tissue engineering, Mater.Sci. Eng. 63, 274- 284 (2016). https://doi.org /10.1016/j.msec.2016.02.071

31. lijima, R. Suzuki, A. lizuka, H. Uenoyokohata, Surface functionalization of tissue culture polystyrene plates with hydroxyapatite under body fluid conditions and its effect on differentiation behaviors of mesenchyme stem cells, Colloids Surf. B. 147, 351-359 (2016). https://doi.org/ 10.1016/j.colsurfb.2016.08.020

32. Wu, B. Su, W. Zhang, C. Wang, In vitro behaviors of hydroxyapatite reinforced polyvinyl alcohol hydrogel composite, Materials Chemistry and Physics. 107, 364-369 (2008). https://doi.org/ 10.1016/j.matchemphys.2007.07.028

33. Pan, D., Xiong Friction properties of nano-hydroxyapatite reinforced (polyvinyl alcohol) gel composites as an articular cartilage. Wear. 266, 699-703 (2009). https://doi.org/10.1016/j.wear.2008.08.012

34. Kobayashi, Y.S. Chang, M. Oka, A two year in vivo study of polyvinyl alcohol hydrogel (PVA-H) artificial meniscus, Biomaterials. 26, 3243-3248 (2005). https://doi.org /10.1016/j.biomaterials.2004.08.028

35. Abdal-hay, C. In-Kim, J. Kyoo-Lim, An in situ hydrothermal fabrication process of poly (vinyl alcohol)/apatite-like nanocomposites with improved thermal and mechanical properties, Ceram. Int. 40, 4995-5000 (2014). https://doi.org /10.1016/j.ceramint.2013.08.057.

36. Ye, P. Mohanty, G. Ghosh, Biomimetic apatite-coated porous PVA scaffolds promote the growth of breast cancer cells, Mater. Sci. Eng. C. 441, 310-316 (2014) https://doi.org/10.1016/j.msec.2014.08.044

37. Qi, S. Musetti, L.H. Fu, Y. Zhu, L. Huang, Biomolecule-assisted green synthesis of nanostructured calcium phosphates and their biomedical applications, Chem. Soc. Rev. 48 2698-2737, (2019), https://doi.org/10.1039/c8cs00489g.

38. Sinha, G. Das, B.K. Sharma, R.P. Roy, A.K. Pramanick, S. Nayar, Poly(vinyl alcohol)-hydroxyapatite biomimetic scaffold for tissue regeneration, Mater. Sci. Eng. C 27, 70 (2007). https://doi.org/10.1016/j.msec.2006.02.008

39. E. Millon, H. Mohammadi, W.K. Wan, Anisotropic polyvinyl alcohol hydrogel for cardiovascular applications, J. Biomed. Mater. Res. Part B: Appl. Biomater. 79, 305 (2006). 
https://doi.org/10.1002/jbm.b.30543

40. Liao, X. Duan et al., Synthesis and Mechanism of Tetracalcium Phosphate from Nanocrystalline Precurso, J. Nanomater, 1, 11 (2014), https://doi.org/10.1155/2014/840102

41. Shirin Akter, M. Yousuf, A. Mollah, A. Samina, Nano-Hydroxyapatite Prepared from Eggshell-Derived CalciumPrecursor using Reverse Microemulsions as Nanoreactor Biomater. Artif. Organs. 4, 54975506 (2017) https://doi.org/10.1016/j.matpr.2017.06.005

42. C. El Idrissi et al., Characterization of silicon-substituted hydroxyapatite powders synthesized by a wet precipitation method, IOSR Journal of Applied Chemistry, 7, 107-112 (2014).

43. Collins Arun Prakash, I. Venda, V. Thamizharasi, E. Sathya, A comparative study on microemulsion synthesis of hydroxyapatite powders by ionic and Non-lonic surfactants, Mater. Today proceeding 2021. https://doi.org/10.1016/j.matpr.2020.10.026.

\section{Figures}

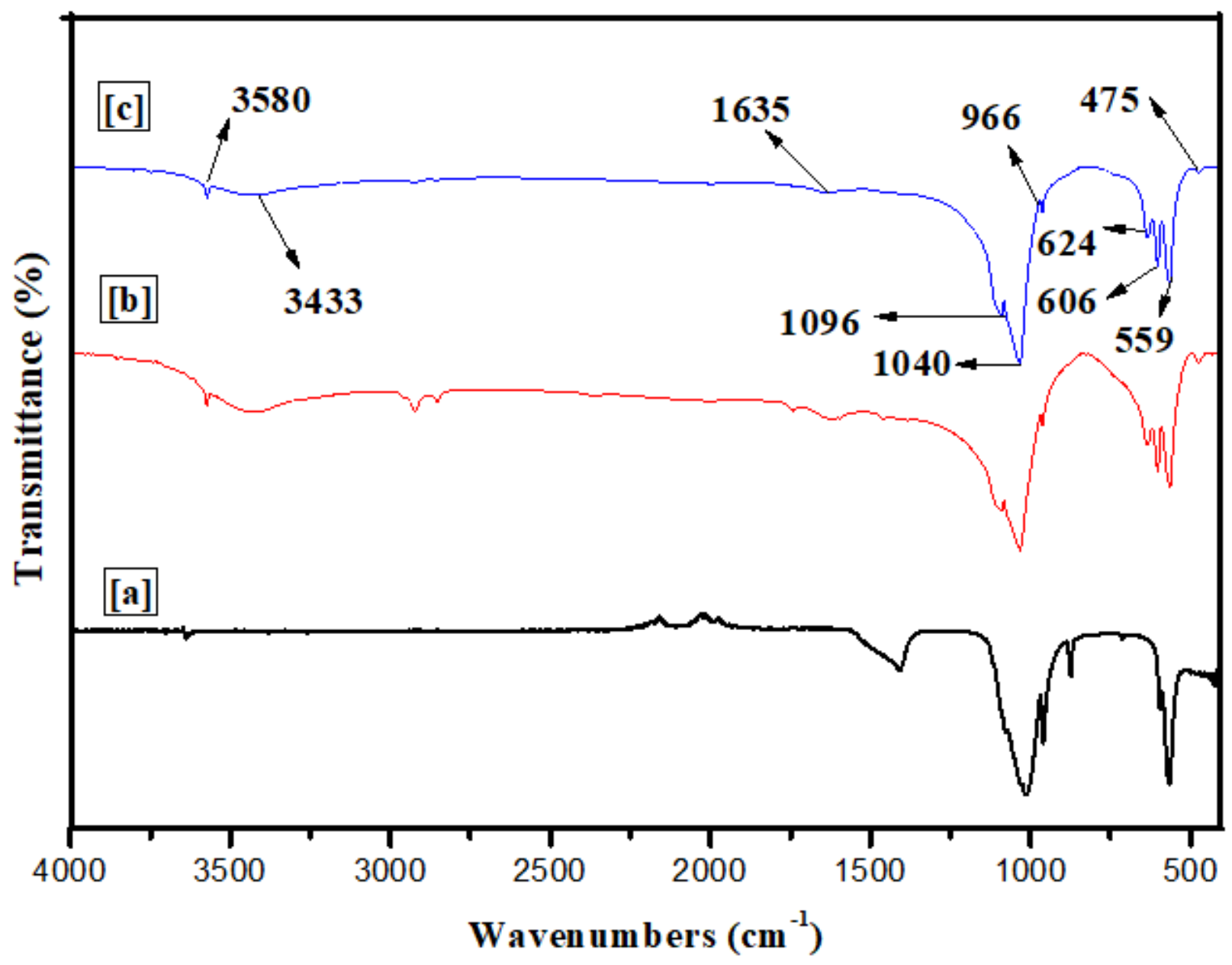

Figure 1 
FTIR spectrum of HAP powder prepared by hydrothermal coupled microemulsion method: (a) HAP, (b) HAP with PVA and (c) PVA-Sr - HAP.

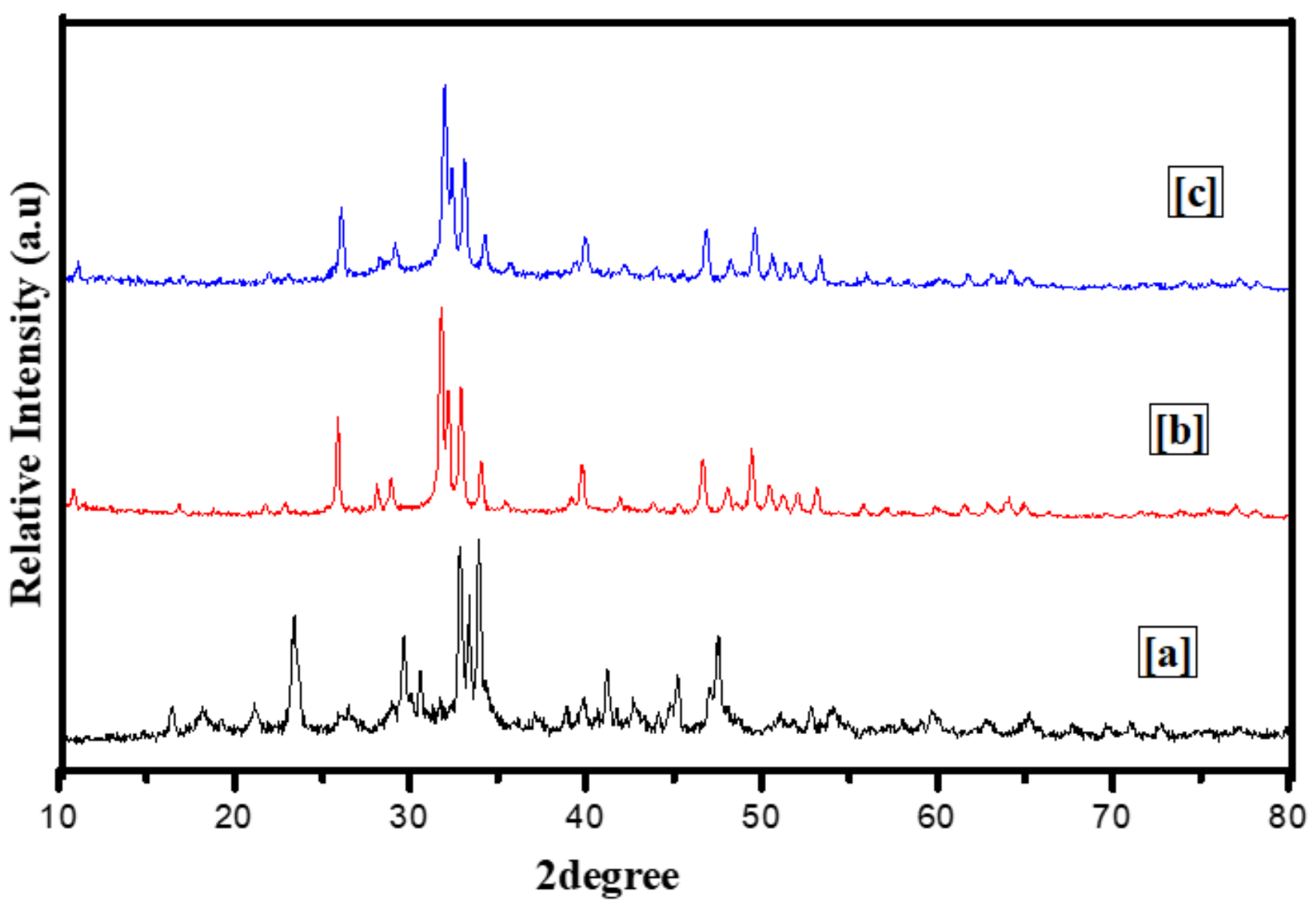

Figure 2

XRD pattern of HAP powder prepared by hydrothermal coupled microemulsion method: (a) HAP, (b) HAP with PVA and (c) PVA-Sr - HAP.
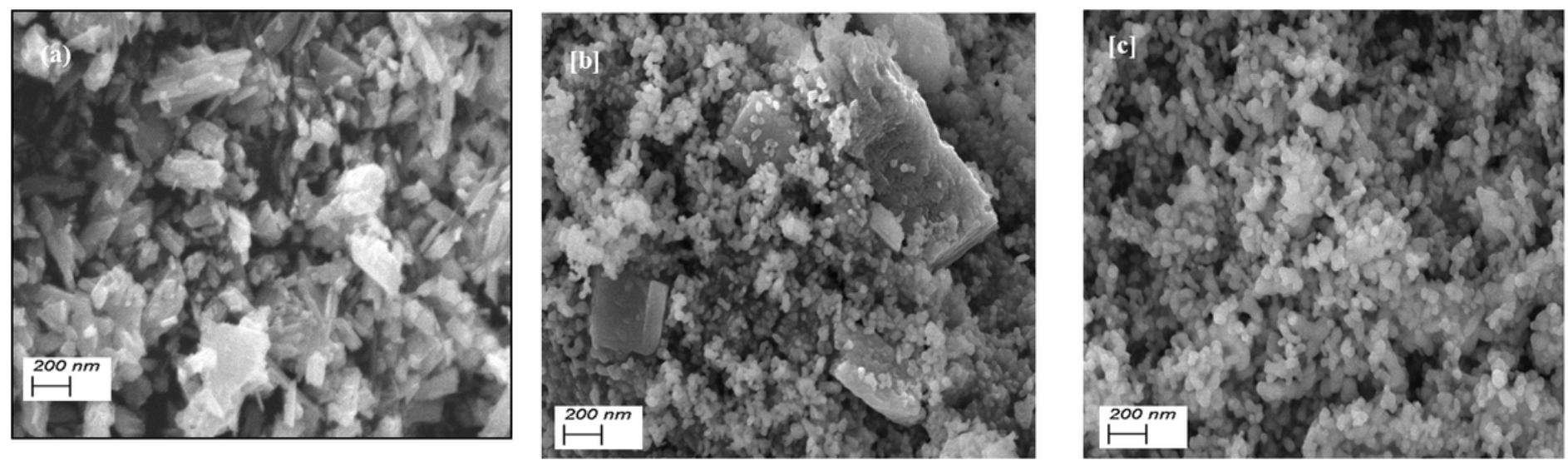

Figure 3 
The SEM image of hydroxyapatite powder prepared by hydrothermal coupled microemulsion method: (a) HAP, (b) HAP with PVA and (c) PVA-Sr- HAP.
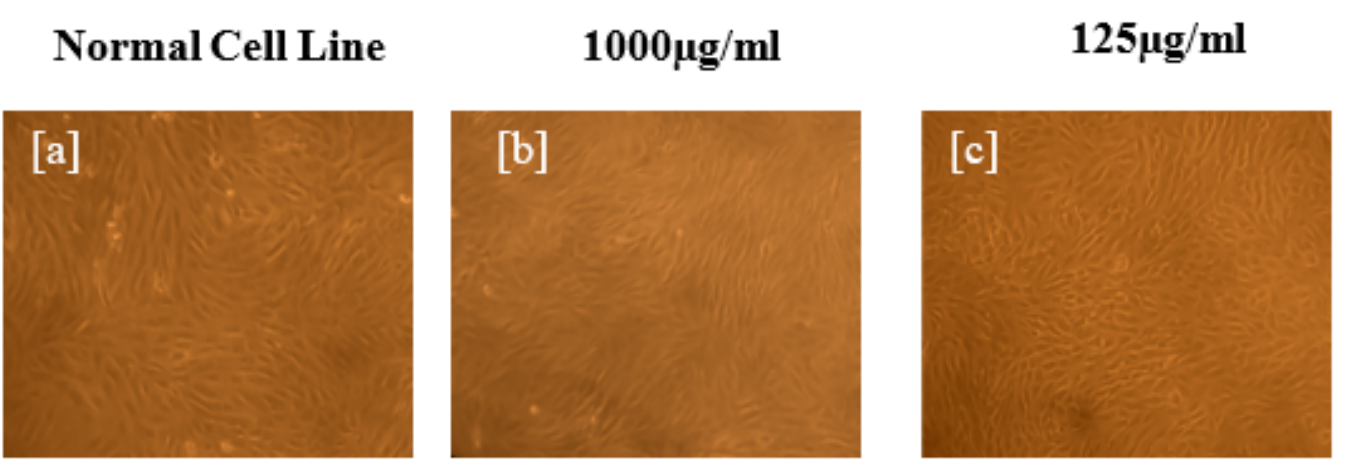

\section{$7.8 \mu \mathrm{g} / \mathrm{ml}$}
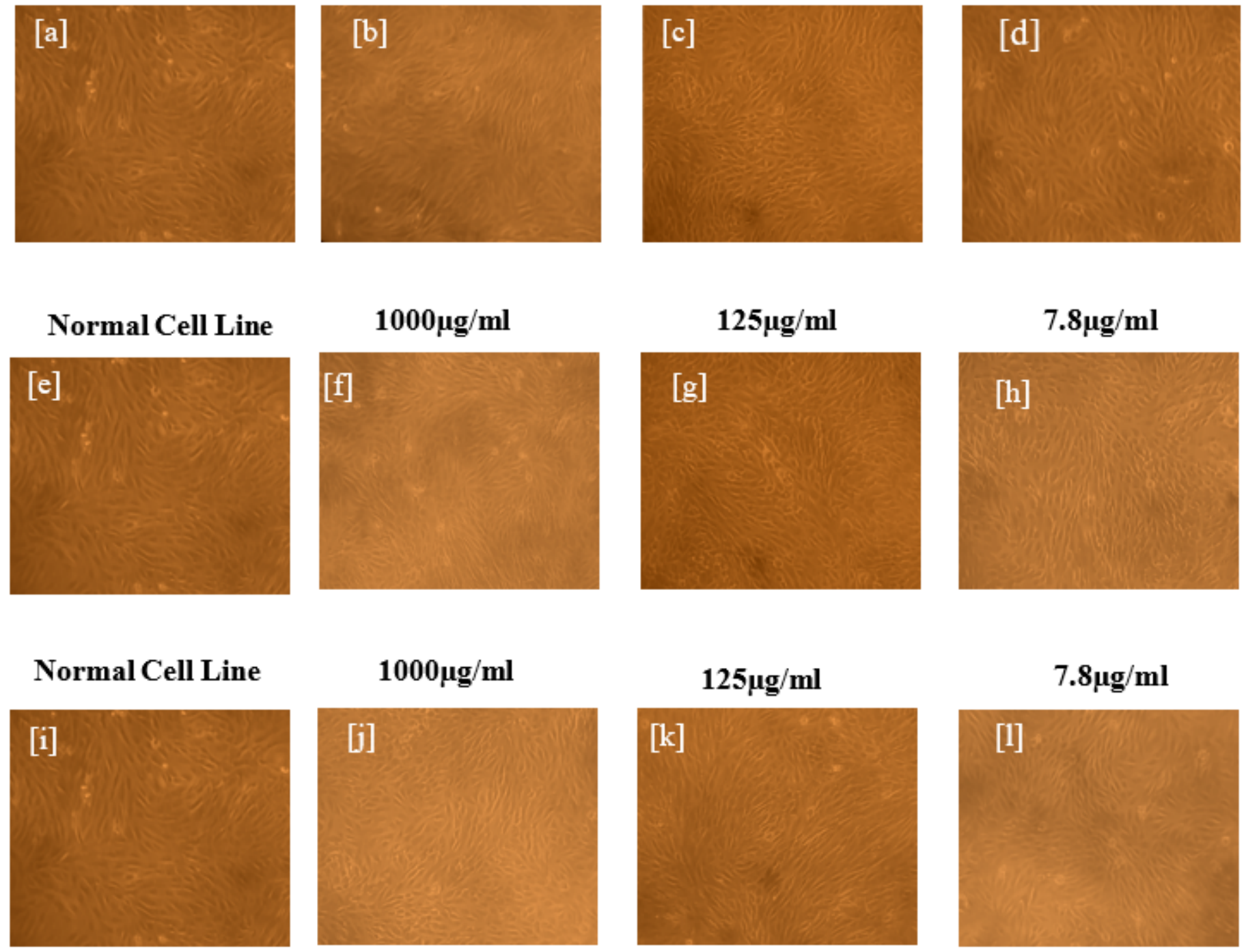

\section{Figure 4}

Proliferation analysis of PVA assisted Sr -hydroxyapatite powder on MG 63 cell line [a] 24 hrs (a-d), [b] 48 hrs (e-h) and [c] 72 hrs (i-I). 


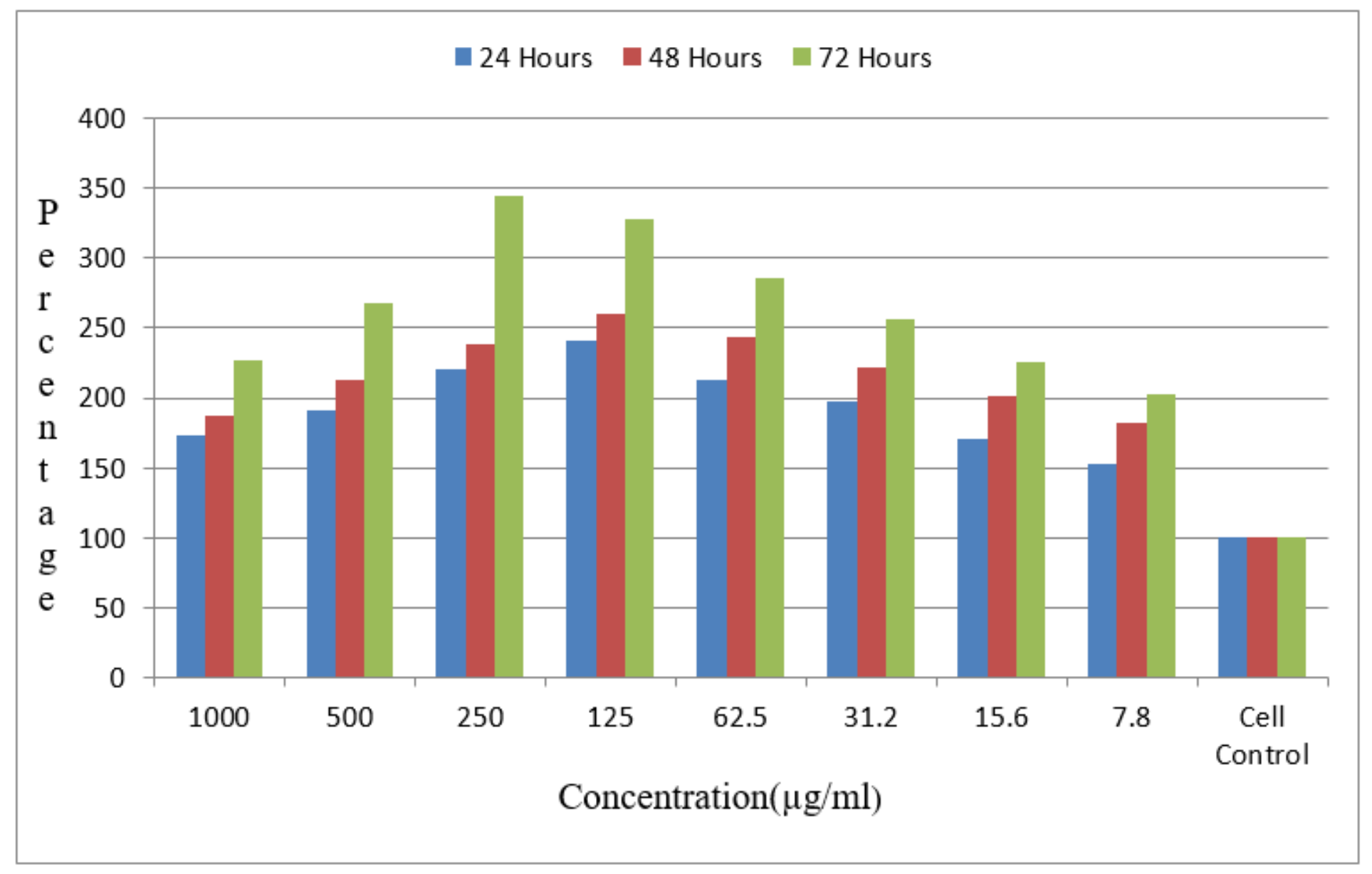

\section{Figure 5}

The comparison graph of PVA assisted Sr -hydroxyapatite powder on MG 63 cell line [a] $24 \mathrm{hrs}$, [b] $48 \mathrm{hrs}$ and [c] 72 hrs.

\section{Supplementary Files}

This is a list of supplementary files associated with this preprint. Click to download.

- GraphicalAbstract.docx 